\title{
SUSTAINABLE CULTURAL TOURISM AND HERITAGE CONSERVATION IN CHINA: CASE STUDIES OF THE ANCIENT WATERFRONT TOWNS IN THE SOUTH OF THE YANGTZE RIVER
}

\author{
SHIQI LIU \& HONGMING SHU \\ Department of Architecture, Built Environment \& Construction Engineering, \\ University of Politecnico di Milano, Italy
}

\begin{abstract}
Sustainable tourism should be established on the basis of the balance between environment, economy and social culture. Nowadays, cultural tourism is growing rapidly in China, and is closely related to heritage conservation. On the one hand, cultural heritage constitutes basic resources to attract visitors in cultural tourism. On the other hand, cultural tourism can bring funds and public awareness for heritage conservation. However, cultural heritage faced several challenges in the process of tourism development. For example, excessive commercialization leads to the loss of local characteristics in historical towns. The research question is how can historic towns preserve their local characteristics in tourism development? The key point of sustainable cultural tourism is to respect the cultural value of cultural heritage, starting from defining the concept of conservation through analyzing good practices. This study investigates ancient waterfront towns in the south of the Yangtze River in China, including Zhouzhuang, Tongli, Wuzhen, and Xitang, and analyzes how four different waterfront towns can maintain their own local characteristics in tourism development, and the role of sustainable tourism in the process. The aim is to propose a series of recommendations to achieve sustainable tourism use of the cultural heritage, with social, economic and cultural advantages for the region involved.

Keywords: sustainable tourism, heritage conservation, cultural tourism, ancient Chinese waterfront towns.
\end{abstract}

\section{INTRODUCTION}

The tourism industry is closely linked to cultural heritage. The original form of tourism is the "Grand Tour", which is a form of education that a gentleman traveled through the cultural centers of the continent predominantly in France and Italy. In 2001, the UNWTO Report on Cultural Heritage and Tourism Development [1] highlighted that: "Culture and tourism have a symbiotic relationship. Arts and crafts, dances, rituals, and legends which are at risk of being forgotten by the younger generation may be revitalized when tourists show a keen interest in them. Monuments and cultural relics may be preserved by using funds generated by tourism. In fact, those monuments and relics which have been abandoned suffer decay from lack of visitation".

As a new consumption style, cultural tourism is one of the largest and fastest growing global tourism markets. Cultural tourism as a significant source of economic growth and overall development of communities for many countries and regions, especially the developing countries. Cultural heritage and cultural tourism have close relationships. Cultural heritage constitutes basic resources to attract visitors in cultural tourism. Cultural tourism can bring funds and public awareness for heritage conservation. The main purpose of this paper is to study the relationships among three key concepts: cultural heritage, cultural tourism and sustainability. The key point of sustainable cultural tourism is to respect the cultural value of cultural heritage, starting from defining the concept of conservation through analyzing good practices. This study investigates ancient waterfront towns in the south of the 
Yangtze River in China, including Zhouzhuang, Tongli, Wuzhen, and Xitang, to think about the compatibility among sustainability, tourism, and heritage as well as how four different waterfront towns can preserve the local identity in tourism development. The aim is to propose a series of recommendations to achieve sustainable tourism use of the cultural heritage, with social, economic and cultural advantages for the region involved.

\section{SUSTAINABLE CULTURAL TOURISM AND CULTURAL HERITAGE}

\subsection{Cultural tourism}

The ICOMOS (International Council on Monuments and Sites) [2] defined cultural tourism as "that activity which enables people to experience the different ways of life of other people, thereby gaining at first hand an understanding of their customs, traditions, the physical environment, the intellectual ideas and those places of architectural, historic, archaeological or other cultural significance which remain from earlier times. Cultural tourism differs from recreational tourism in that it seeks to gain an understanding or appreciation of the nature of the place being visited". In this framework, historic towns and villages became one of the most important heritage assets, because they are the integration of tangible and intangible heritage and better interpret the complexity of the human relationship with the environment.

A comprehensive review of cultural tourism definitions has recently been by Mousavi et al. [3]. Most of these definitions have been designed to serve different purposes, synthetically consider that "cultural tourism involves the consumption of a wide range of cultural manifestations like heritage, art, folklore etc. by tourists. Cultural tourism can be generally seen as a sociocultural relationship between people which is promoted, moderated and mediated by a range of various actors including, planners, politicians, researchers, marketing professionals, travel agencies and so on". According to this conceptual definition, cultural tourism covers not just the "heritage tourism", which is the consumption of the cultural products of the past, but also contemporary culture or the "way of life" of the people or region. Ddictví and Kajzar [4] divided cultural tourism into seven types: heritage tourism, cultural thematic routes, cultural city tourism, traditions and ethnic tourism, event and festival tourism, religious tourism, and creative tourism.

\subsection{Sustainable cultural tourism}

The most widely used definition of sustainable development by the Brundtland Commission in 1987 [5], which consider that "development must meet the needs of current generations without compromising the ability of future generations to meet their own needs". Sustainable cultural tourism is closely linked to the sustainable use of cultural heritage, which includes the conservation and management of cultural heritage. As Buckley [6] argues: "sustainable tourism as a way of reconciling tensions and balancing various aspects of heritage conservation, tourism management, social pressures, and economic development". Sustainable tourism should be established on the basis of the balance among environment, economy and social culture (Fig. 1).

Another definition of sustainable tourism in a holistic perspective was defined by Briassoulis [7] highlighted that sustainable cultural tourism is a way of management of cultural heritage and cultural tourism. In order to meet fundamental criteria of promoting local development, securing their self-sufficiency, and satisfying the needs of tourists. 


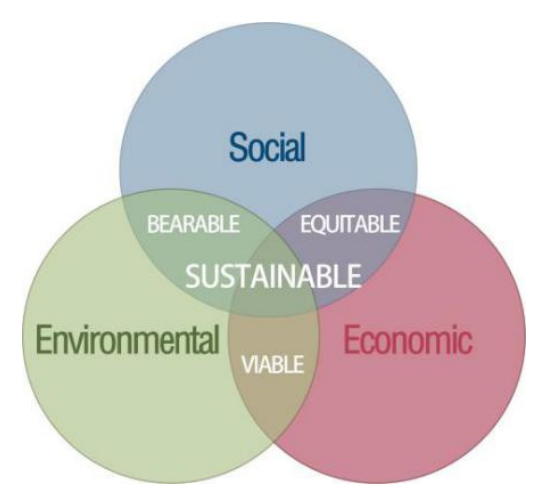

Figure 1: Scheme of sustainable development: at the confluence of three constituent parts [6].

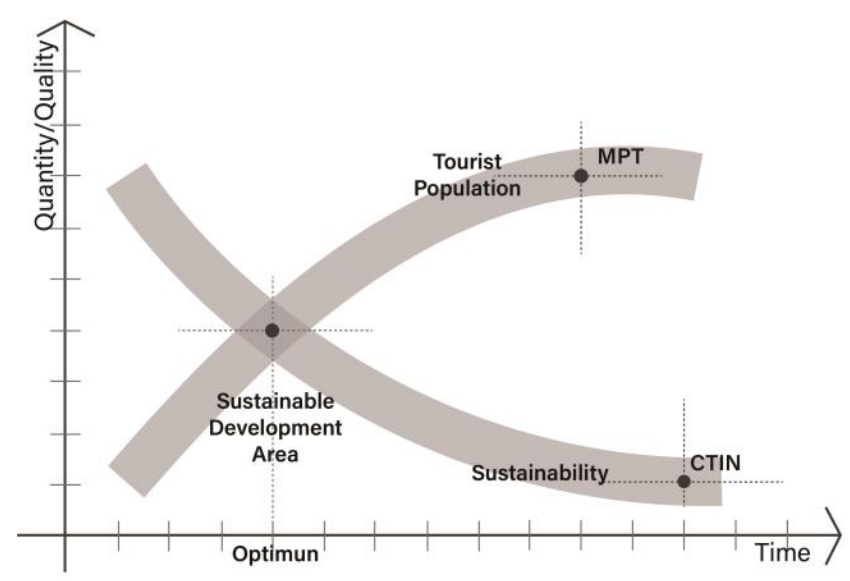

Figure 2: Sustainable development area [8].

Lawrence [8] points to the quality of tourist's experience in tourist destinations that influences future attraction in these places and this process is the so-called "tourist cycle" (Fig. 2). If tourists give good comments in these places, it will increase future attraction and the number of tourists visits these areas. As this figure increases, the influences of tourism on the social and environmental quality increase accordingly. Thus, excessive tourists will make it reaching degradation levels.

However, too many tourists will accelerate the damage of cultural heritage, and excessive commercialization will adversely affect the authenticity of built heritage as well. If the cultural heritage is not properly preserved, it will affect the experience of cultural tourists, and these negative aspects will lead to a decline in sustainability and will take a long period of time to revert. If the number of tourists and the negative impacts do not exceed the maximum levels, sustainable cultural tourism development can be reached in the long term. Actually many tourism projects seek maximum economic income and ignored the recommended limits. Sustainable cultural tourism is a way of management, which is to control the number of tourists and the negative impacts do not exceed the maximum levels. 


\subsection{The relationship between cultural tourism and cultural heritage}

As Conti [9] noted, the close relationship between cultural tourism and heritage brings benefits and opportunities, but could also become a threat to heritage integrity and values if not properly planned, such as excessive tourists, the risk of developing a pseudo-cultural tourist offer, alteration or destruction of material components of buildings and progressive loss of its cultural identity. The conservation of cultural heritage requires a lot of money, and cultural tourism can provide funds for heritage conservation. Amarilla and Conti [10] highlighted that conservation at any cost is not practical, especially in developing countries, the financial funds which are spent on conservation can be used to solve basic problems for health care, food, housing.

The main approach of current heritage utilization in China is to develop tourism. In order to specify the relationship between heritage and cultural tourism in China, a comprehensive analysis of China's cultural tourism policies from 2009 to 2017 has recently been by Liu [11], three characteristics are summarized, that is combining culture industry and tourism industry to expand cultural consumption market; emphasizing the conservation of cultural heritage in the development of cultural tourism; to enhance the culture connotation and local characteristics to creating a boutique tourism brand. Therefore, China's State Council promulgated "Some Opinions on Further Promoting Tourism Investment and Consumption" in August 2015, to emphasize the combination between tourism and cultural heritage preservation, and to lead and normalize the development of famous historic cities and towns. These situations are taken to rethink how the possibilities for a sustainable relationship and how the planned and implemented of heritage utilization can ensure sustainability.

\section{CASE STUDIES OF THE ANCIENT WATERFRONT TOWNS IN THE SOUTH OF THE YANGTZE RIVER}

\subsection{Ancient waterfront towns}

The ancient waterfront towns are in the south of the Yangtze River and near Taihu Lake, which area is one of the most industrialized and urbanized regions in China. In November 2012, eight of the ancient waterfront towns, Zhouzhuang, Tongli, Luzhi, Jinxi, Qiandeng, Wuzhen, Xitang, and Nanxun are listed in the tentative list for World Cultural Heritage of China, announced by the State Administration of Cultural Heritage. At present, the ancient waterfront towns serve as cultural heritage resources for cultural tourism and become world famous tourist destinations, and branded as the "Venice of the East". As Ma et al. [12] noted, during the nearly 20 years, more waterfront towns have entered the tourism market and shaping a pattern dominated by the six largest water towns. As Fig. 3 indicates, the number of ancient waterfront towns development tourism which growth was particularly sharp between 2000 and 2005. And the number of tourists arrivals increased rapidly in 2010, nearly 30 million, because of the Shanghai World Expo.

The case study focuses on the four ancient waterfront towns (Fig. 4), Zhouzhuang, Tongli, Wuzhen, and Xitang, which are the most famous and popular waterfront towns in the tourism market. The local government sets up an operating company vested for managing tourist business. Tourists are charged an entrance fee to visit the town's core area of cultural heritage.

As indicated in Table 1, Zhouzhuang is the most popular tourist destination among 4 ancient waterfront towns, while it was once an unknown and poor waterfront town in east China's Jiangsu province, with less infrastructure for gas, electricity and private toilets, etc., 


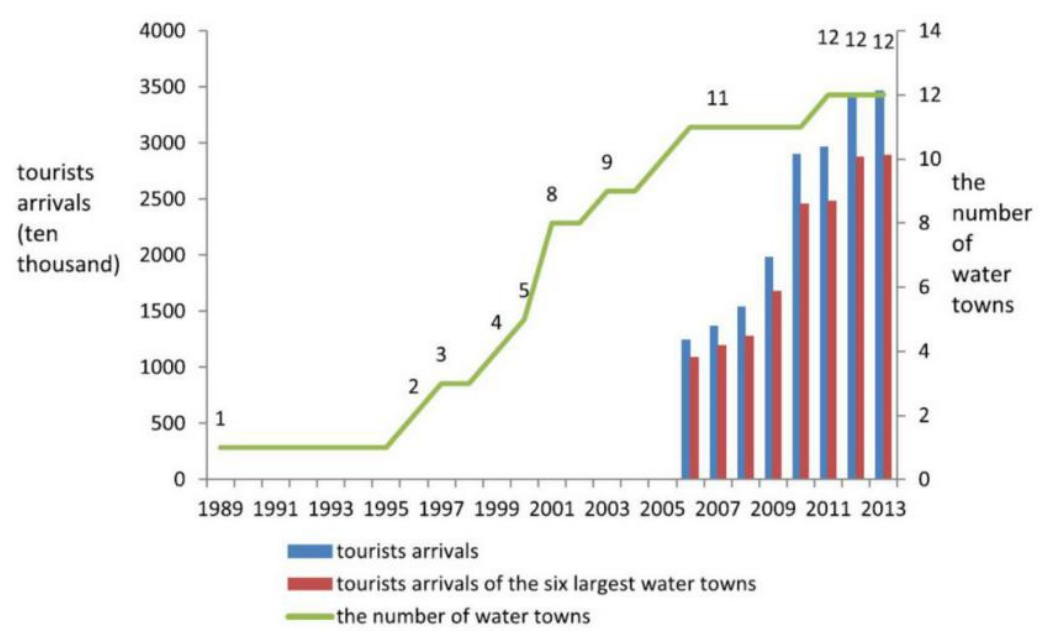

Figure 3: Tourists arrivals and the ancient waterfront towns tourism market [12].

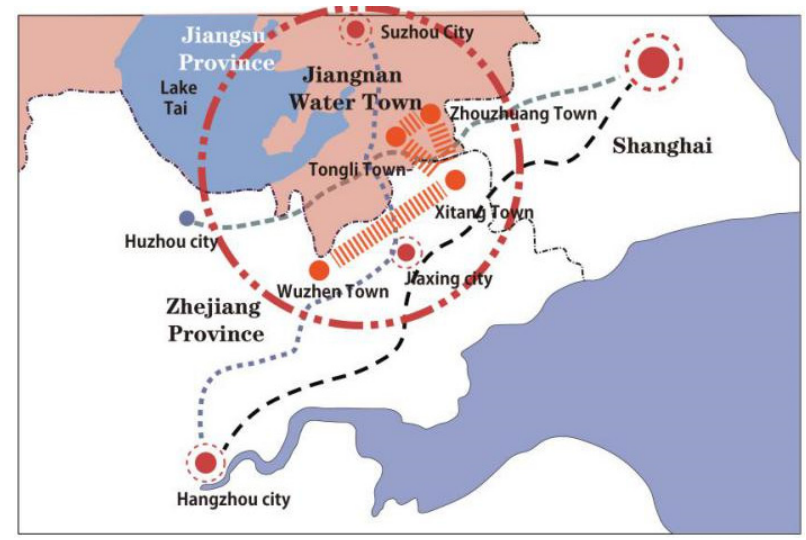

Figure 4: Geographical locations of selected ancient waterfront towns.

Table 1: Ticket price and tourists of ancient waterfront towns [12].

\begin{tabular}{|l|c|c|c|c|}
\hline & Zhouzhuang & Tongli & Wuzhen & Xitang \\
\hline Ticket price (yuan) & 100 & 80 & 150 & 100 \\
\hline Tourists arrivals (million) & 5.92 & 5.02 & 5.47 & 2.69 \\
\hline
\end{tabular}

lack of funds to conservation, with no public awareness of conservation and appreciation for their heritage.

\subsection{Tourism, conservation and economic valorization of waterfront towns}

The conservation and tourism development of the ancient waterfront towns is pursuing a mission of "balancing heritage protection and tourism development" and with the idea of 
maintaining the ancient towns as a "living body", which advocated by Professor Yisan Ruan at the College of Architecture and Urban Planning at Tongji University. He is one of the most important planners and experts to get involved with the conservation of historic water towns by assisting local people. As good practices, the ancient waterfront towns in the south of the Yangtze River brought funds and public awareness for cultural heritage conservation through developing tourism. It has been emulated by many other historic towns and villages in China during the past decades.

\subsubsection{Conservation principles in China}

The key point of sustainable cultural tourism is to respect the cultural value of built heritage, starting from defining the concept of conservation. After reviewing international principles of heritage conservation and authenticity, this paper specifies the conservation principles and problems of built heritage conservation in China. According to Article 9 of the Venice Charter [13], restoration can be defined as "to preserve and reveal the aesthetic and historic value of the monument and is based on respect for original material and authentic documents". In 1999, According to Paragraph 9 of the ICOMOS [14] International Wood Committee's Principles for the Preservation of Historic Timber Structures, "In the repair of a historic structure, replacement timber can be used with respect to relevant historical and aesthetical values, and where it is an appropriate response to the need to replace decayed or damaged members or their parts, or to the requirements of restoration". Paragraph 10 noted that: "It should be accepted that new members or parts of members will be distinguishable from the existing ones". The Chinese conservation scene has attempted to define its own authenticity criteria through learning from both its history of restoration and from international principles. Zhu [15] argues “The principle of conservation in China is 'restoring the old as it was' (修 旧如旧 xiujiu rujiu) follow to conserve a site's 'historic condition', including different stages of its history. The Old Chinese practice forgoes the need to distinguish between new members and original members of historical timber structures. The need for replacement or the requirements of restoration is hybrid understood as the concern for historical and esthetic values" (shown in Fig. 5).

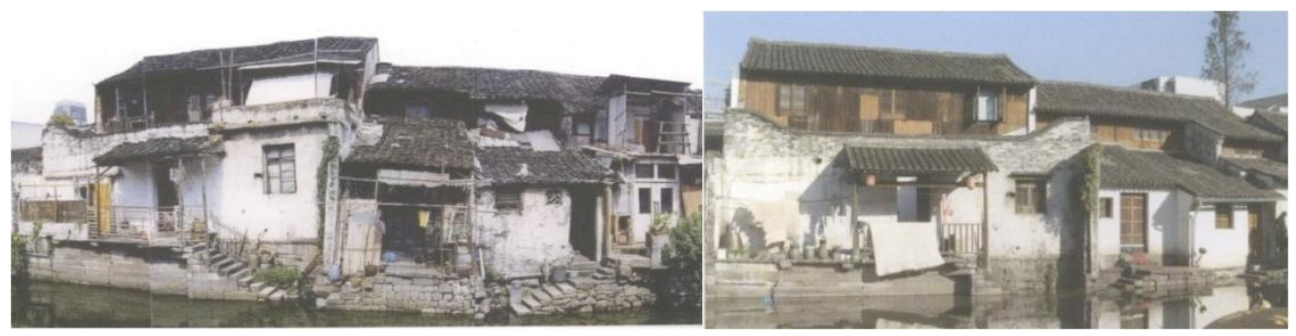

Figure 5: Conservation of the historic district, Huangshanhe, Shaoxing city (before and after conservation) [18].

The modernization and urbanization in China presented new challenges for built heritage conservation in the country. Some local authorities and tourism projects have misunderstood the interpretations of the notion, transforming it into "making something look old". Thus, the quest for cultural tourism and heritage has taken on a dynamic and diversified form through local economic, social, and cultural development. Some tourism projects attract tourists through the archaizing buildings, reconstructing and performing cultural heritage. 


\subsubsection{Conservation and tourism development of waterfront towns}

The first conservation of the ancient waterfront town project of Professor Ruan was initiated in 1986 with the master plan and town protection plan of Zhouzhuang. Zhouzhuang is also the earliest town to develop tourism among four ancient waterfront towns in the south of the Yangtze River. During the conservation of Zhouzhuang, Professor Ruan advocated that "to fully utilize the human, cultural and historical resources in order to increase the town's cultural characteristics for tourist purposes". On April 1, 1989, "Shengting House" (Fig. 6), architecture from the Qing dynasty in Zhouzhuang, was officially opened to the public after five years of difficult restoration, thus opening the prelude to the development tourism of the ancient waterfront towns.
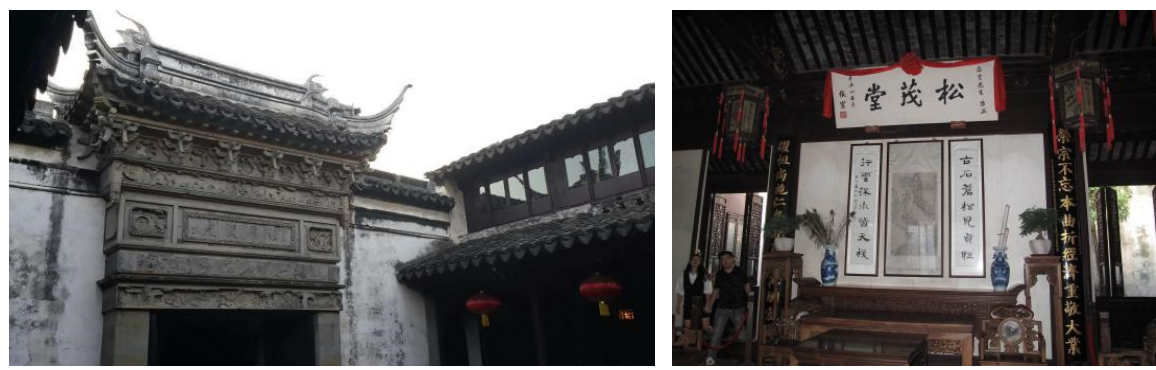

Figure 6: Shenting House, Zhouzhuang.

Zhouzhuang has been a commercial town since ancient times. In the tourism development of Zhouzhuang, jobs are increased and local people's interests are protected, thus many local people can be retained. Now it is famous for traditional commercial streets, which is the core of local people's life. The architectural features of Zhouzhuang are that the ancient buildings are wooden structure with double-story in traditional commercial streets (Fig. 7), which the downstairs of the building is a store, the upstairs is a housing or the front part of the building is a shop, while the back part is housing, and often running in parallel to the river. As Porfyriou [16] noted that "the 'bridge-water-house' trinity represents a typical feature of these water towns" (Fig. 7). Another typical characteristics is the overall layout of the ancient waterfront towns. Different types and characteristics of ancient waterfront towns had evolved from the different forms of water bodies nearby, which is the main feature that attracts tourists.

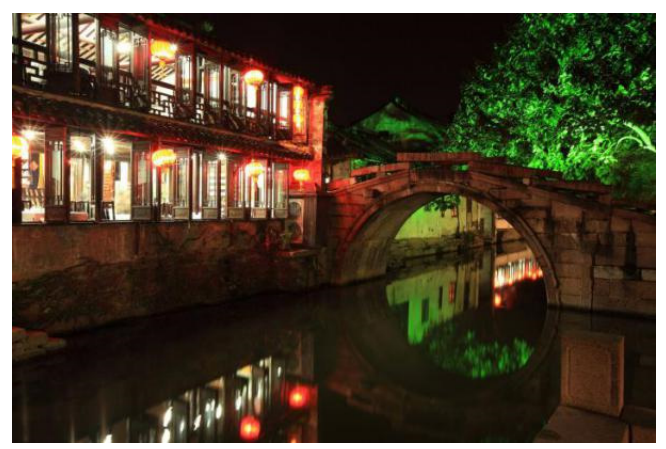

Figure 7: The "bridge-water-house" trinity, Wuzhen. 
As Yisan et al. [17] summarised their development patterns of the ancient waterfront town. The layout of the strip-shaped ancient waterfront town is formed along a single river channel. The plan of the ancient town is linearly distributed. Generally, the scale is small. The main buildings were constructed along the river. The streets are parallel to the river and form a virtual space with the building. The layout of the cross-shaped or tree-crotch-shaped town is formed along two or more rivers, Generally medium-sized, a cross-shaped town such as Wuzhen (Fig. 8). The layout of the grid-shaped towns is formed along four or even more rivers running through the town, such as Tongli (Fig. 9).
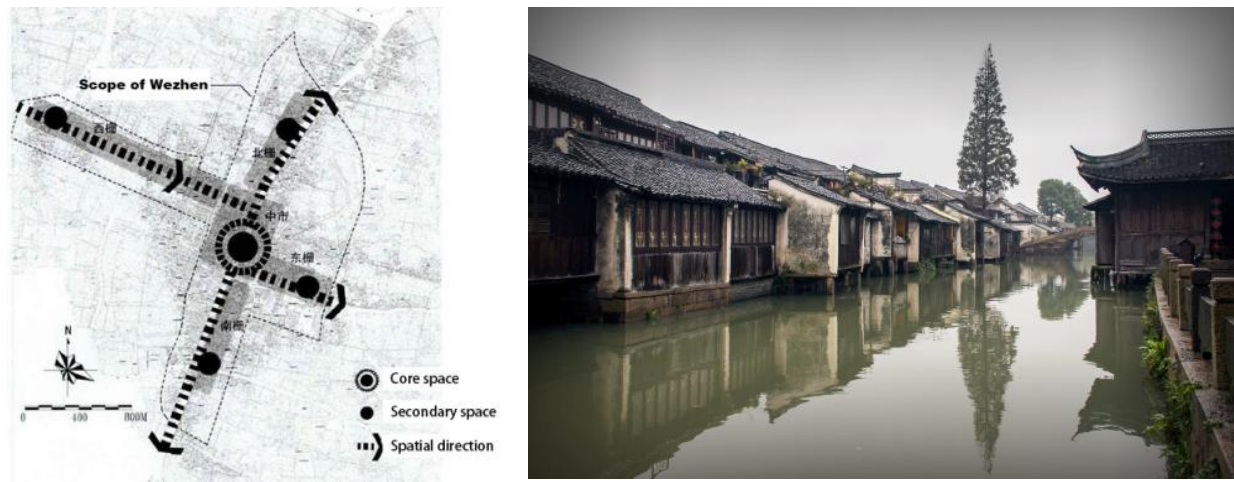

Figure 8: The layout of the cross-shaped town, Wuzhen [17].

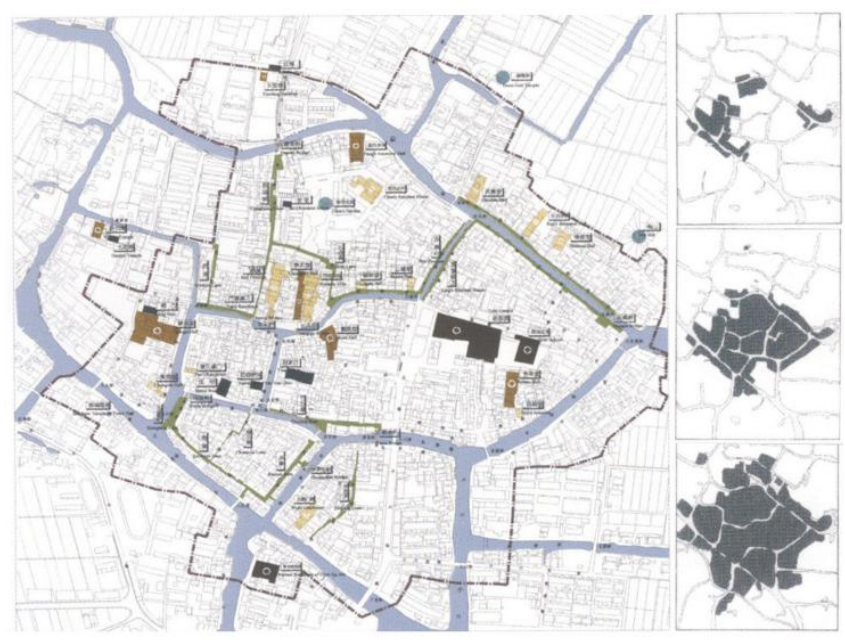

Figure 9: The layout of the grid-shaped town, Tongli [17].

As Shaoyong [18] noted that in the past the water is the important traffic and street network of water towns, most commercial activities took place on the water network. With the continuous development of highway networks and air transportation, the function of canal networks has declined or even disappeared. The water network is now mainly responsible for the development of tourism and related services. 
At present, the model of tourism development and conservation in ancient waterfront towns can be roughly divided into three types (Fig. 10): The first is focusing on tourism and commercial development, such as Zhouzhuang, an original commercial town since ancient times. The main problem is excessive commercialization. The second focuses on protecting the interests of the local people and retaining the people, such as Tongli and Xitang. Besides the conservation and promotion of their own characteristics, these two water towns still retain the "way of life" of the region. The third type, like Wuzhen, focuses mainly on the meticulous conservation of built heritage, without considering the interests of the local people. Thus, the local people move out, and the ancient towns lost the "way of life" of the local people.

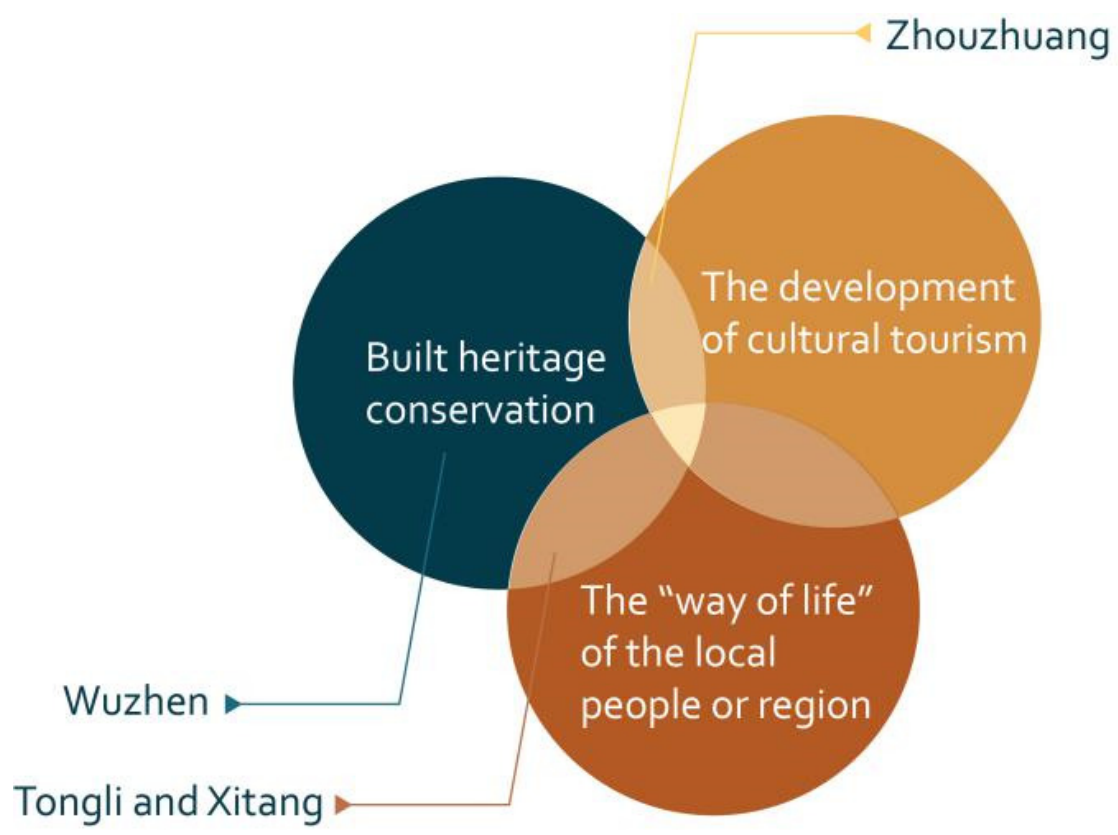

Figure 10: Three types of the ancient waterfront towns.

The critical assessment of the tourism development of the ancient waterfront towns is that it also gives scope for local governments and invest tourism companies more interested in the economic returns. Thus it may intervene in heritage conservation, to misinterpret the ideas of architects and planners. Resulting in the conservation process that has focused on the town's core area of cultural heritage, which can be charged an entrance fee to visit the town, rather than conservation the whole town.

\section{THE METHODS FOR SUSTAINABLE CULTURAL TOURISM AND CONSERVATION}

After comparing the four cases, this paper assesses them from the three aspects: social, economical, cultural and 18 corresponding factors (Table 2). The local cultural industry, cultural innovation and retains the "way of life" of the local people or region should be improved. Pursuing economic returns cause the commercialization of the towns, and may intervene in built heritage conservation and cause cultural identity problems. 
Table 2: Case comparison of waterfront towns.

\begin{tabular}{|c|c|c|c|c|c|}
\hline Aspects & Factors & Zhouzhuang & Wuzhen & Tongli & Xitang \\
\hline \multirow{6}{*}{ Social } & Government support & $\sqrt{ }$ & $\sqrt{ }$ & $\sqrt{ }$ & $\sqrt{ }$ \\
\hline & Local people support & $\sqrt{ }($ excellent $)$ & $\begin{array}{l}- \text { (to be } \\
\text { improved) }\end{array}$ & $\sqrt{ }$ & $\sqrt{ }$ \\
\hline & $\begin{array}{l}\text { High retention rate for local } \\
\text { people }\end{array}$ & $\sqrt{ }$ & - & $\sqrt{ }$ & $\sqrt{ }$ \\
\hline & Local development & $\sqrt{ }$ & $\sqrt{ }$ & $\sqrt{ }$ & $\sqrt{ }$ \\
\hline & $\begin{array}{l}\text { Improvement of facilities and } \\
\text { infrastructure }\end{array}$ & $\sqrt{ }$ & $\sqrt{ }$ & $\sqrt{ }$ & $\sqrt{ }$ \\
\hline & Social media promotion & $\sqrt{ }$ & $\sqrt{ }$ & - & - \\
\hline \multirow{6}{*}{ Economical } & Commercialization & $\sqrt{ }$ & $\sqrt{ }$ & - & - \\
\hline & Creation jobs & $\sqrt{ }$ & - & $\sqrt{ }$ & $\sqrt{ }$ \\
\hline & Number of tourists & $\sqrt{ }$ & $\sqrt{ }$ & $\sqrt{ }$ & $\sqrt{ }$ \\
\hline & Investment & $\sqrt{ }$ & $\sqrt{ }$ & $\sqrt{ }$ & $\sqrt{ }$ \\
\hline & Boutique tourism brand & $\sqrt{ }$ & $\sqrt{ }$ & - & - \\
\hline & $\begin{array}{l}\text { Increase of local people's } \\
\text { income }\end{array}$ & $\sqrt{ }$ & - & $\sqrt{ }$ & $\sqrt{ }$ \\
\hline \multirow{6}{*}{ Cultural } & Built heritage & $\sqrt{ }$ & $\sqrt{ }$ & $\sqrt{ }$ & $\sqrt{ }$ \\
\hline & Cultural identity & - & - & - & - \\
\hline & Cultural innovation & - & - & - & - \\
\hline & Local characteristics & $\sqrt{ }$ & $\sqrt{ }$ & $\sqrt{ }$ & $\sqrt{ }$ \\
\hline & Local cultural industry & - & - & - & - \\
\hline & $\begin{array}{l}\text { "Way of life" of a people or } \\
\text { region }\end{array}$ & - & - & $\sqrt{ }$ & $\sqrt{ }$ \\
\hline
\end{tabular}

Sustainable cultural tourism should be based on cultural heritage conservation and deal with two aspects: one is the relationship between conservation and local development, and the other is the relationship between tourism and support of local people. Summarised as follows:

1. Conservation and tourism development should get support from the local people through protecting the local people's interests. Tourism development could increase local people's income and raise local people's awareness and appreciation for their heritage, which also reinforced the potentiality for conservation.

2. Focusing on conservation and local development, and developing local's economies through cultural tourism, especially the development of cultural industries.

3. Conservation and management, record and map existing towns in order to plan their conservation, to respect the local identity, and to control the number of tourists and the negative impacts not exceed the maximum levels.

4. Cultural innovation, pay more attention to the inheritance and promotion of traditional culture. Through the cultural innovation, which will be more acceptable for travelers in 
the form of traditional music, dance, drama, folk art, acrobatics and other entertainment, and also serves as the foundation in enhancing the attraction, influence and competitiveness of tourism.

\section{CONCLUSION}

Cultural heritage has become the main tourist attraction in cultural tourism. Sustainable cultural tourism must be based on the protection of cultural heritage to deal with the balance between the two. As a famous tourist attraction of cultural tourism, historical ancient towns must protect both tangible and intangible heritage in the process of sustainable development. At the same time, we must also consider the interests of stakeholders (residents, tourists, public, government), especially the interests of the local people. Only through protecting their interests can they be retained in the ancient towns. Meanwhile, we need to avoid the problem of the commercialization of the transition. Through cultural innovation, it not only increases the experience of cultural tourists, but also inherits folk culture and Chinese traditional culture, and further guarantees the development of sustainable cultural tourism.

\section{ACKNOWLEDGEMENTS}

We are grateful to the Department of Architecture, Built Environment and Construction Engineering of University of Politecnico di Milano for supporting in our research and in particular to Professor Nora Lombardini.

\section{REFERENCES}

[1] UNWTO, Cultural Heritage and Tourism Development, 2001.

[2] ICOMOS, International Cultural Tourism Charter, 1999. www.icomos.org/charters/tourism_e.pdf.

[3] Mousavi, S.S., Doratli, N., Mousavi, S.N. \& Moradiahari, F., Defining cultural tourism. International Conference on Civil, Architecture and Sustainable Development, pp. 70-75, 2016.

[4] Ddictví, K.C.R.A.S. \& Kajzar, I.P., Cultural tourism and world heritage. XVII. mezinárodní kolokvium o regionálních vědách, pp. 901-906, 2014.

[5] Brundtland, G.H., Khalid, M., Agnelli, S., Al-Athel, S. \& Chidzero, B., Our Common Future, New York, 1987.

[6] Buckley, R., Sustainable tourism: Research and reality. Annals of Tourism Research, 39(2), pp. 528-546, 2012.

[7] Briassoulis, H., Sustainable tourism and the question of the commons. Annals of Tourism Research, 29(4), pp. 1065-1085, 2002.

[8] Lawrence, K., Sustainable Tourism Development. Protected Area Economics and Policy: Linking Conservation and Sustainable Development, pp. 263-269, 1994.

[9] Conti, A.L., Cultural heritage and tourism: Possibilities of a sustainable relationship. Past for the Future, 10, pp. 15-23, 2015.

[10] Amarilla, B. \& Conti, A., Built Heritage and Sustainable Tourism: Conceptual, Economic and Social Variables, INTECH Open Access Publisher, 2012.

[11] Liu, S., Cultural tourism policies and development trends in China. Proceedings of the International Symposium Heritage for Planet Earth 2018, pp. 78-82, 2018.

[12] Ma, M., Weng, J. \& Yu, L., Market size, scale economies, and tourism market structure: A case of historic water town tourism in China. Tourism Management, 49, pp. 119-137, 2015. 
[13] ICOMOS, International Charter for the Conservation and Restoration of Monuments and Sites (The Venice Charter), Approved by the Second International Congress of Architects and Technicians of Historic Monuments in Venice from 25 to 31 May 1964, adopted by ICOMOS in 1965. www.icomos.org/charters/venice_e.pdf.

[14] ICOMOS, Principles for the Preservation of Historic Timber Structures, Adopted by ICOMOS at the 12th General Assembly in Mexico, October 1999. www.icomos.org/images/DOCUMENTS/Charters/wood_e.pdf.

[15] Zhu, Y., Authenticity and heritage conservation in China: Translation, interpretation, practices. Authenticity in Architectural Heritage Conservation, pp. 187-200, 2017.

[16] Porfyriou, H., Urban heritage conservation of China's historic water towns and the role of Professor Ruan Yisan: Nanxun, Tongli, and Wuzhen. Heritage, 2(3), pp. 24172443, 2019.

[17] Yisan, R., Zhen, L. \& Lin, L., The Preservation of Historic Buildings and Historic Environment in Jiangnan Ancient Town, People's Fine Arts Publishers: Shanghai, pp. 46-65, 2010.

[18] Shaoyong, Urban Heritage Research and Conservation, Tongji University Publishers: Shanghai, pp. 27-55, 2010. 